\title{
EMPATHY AND CLASSROOM CLIMATE AS PREDICTORS OF STUDENT'S WELL-BEING: AN INTERNATIONAL PILOT STUDY
}

\author{
Manja Veldin ${ }^{1}$, Ana Kozina ${ }^{1}$, Tina Vršnik Perše ${ }^{2}$, Maša Vidmar ${ }^{1}$, Ivana Jugović ${ }^{3}$, \\ \& Magnus Oskarsson ${ }^{4}$ \\ ${ }^{l}$ Educational Research Institute (Slovenia) \\ ${ }^{2}$ Faculty of Education at University of Maribor (Slovenia) \\ ${ }^{3}$ Institute for Social Research in Zagreb (Croatia) \\ ${ }^{4}$ Mid Sweden University (Sweden)
}

\begin{abstract}
One of the key ingredients of social, emotional and intercultural competencies, which contributes significantly to a positive and inclusive classroom climate is empathy (Zorza, 2015). Empathy enables us to understand others and feel connected with them (Eisenberg, et al., 1996). High ability of empathy, which includes cognitive (e.g. taking the perspective of another) and emotional components (e.g. personal distress), is associated with numerous positive effects on relationships and behaviour (e.g. prosocial behaviour), while the lack of it is associated with many negative effects (e.g. aggression) (Davis, 1980). Establishment of positive relationships with others and empathy are associated with psychological well-being of students (Shanafelt et al, 2005). The aim of the present study was to analyse the associations between empathy, perceived classroom climate and well-being among students of the 8th-grade. We will present the analysis from three EU countries ( $N$ : Slovenia: 107, Sweden: 86, and Croatia: 79) who participated in the pilot of the European Erasmus KA3+ Hand in Hand project. We analysed predictive power of empathy (IRI; Davis, 1980) and the perceived classroom climate (Positive class climate; Stöber, 2002) on the well-being (WEMWBS; Stewart-Brown et al., 2011). Results show, that in all countries, personal distress (one component of empathy) is an important predictor of the student's well-being. Results are discussed in light of guidelines for school practice.
\end{abstract}

Keywords: Empathy, classroom climate, well-being, students.

\section{Introduction}

Subjective well-being of students and its predictors have high importance in the promotion of adolescents positive functioning. One of them is empathy (Shanafelt et al., 2005) that enables us to understand others and feel connected with them (Eisenberg, et al., 1996). It represents one of the key ingredients of social, emotional and intercultural (SEI) competencies, which contribute significantly to a positive and inclusive classroom climate (Zorza, 2015). High ability of empathy, which includes cognitive (fantasy and perspective taking) and emotional components (emphatic concern and personal distress) (Davis, 1980), is associated with numerous positive effects on relationships and behaviour (e.g. prosocial behaviour; Decety et al., 2016), while the lack of it is associated with many negative effects (e.g. aggression; Jolliffe \& Farrington, 2006). It has been shown that empathy (and via its positive effect on the positive relationships with others), is connected to higher perceived psychological well-being of students (Shanafelt et al., 2005). Furthermore, the positive classroom climate, which involves positive relationships, classroom management, and structure, is also connected to well-being (Cocoradă \& Orzea, 2017). The aim of the present study was to analyse the associations between empathy, perceived classroom climate and well-being among students of the 8th-grade in three EU countries. 


\section{Method}

\subsection{Participants}

A convenience sample of $8^{\text {th }}$-grade (13 to 14-year-olds) students from three EU countries (N: Slovenia: 107; 47,7 \% males; Sweden: 86; 44,2 \% males; and Croatia: 79; 68,4\% males) were invited to participate in the pilot of the Hand in Hand project, which aims to increase the social, emotional (e.g. self-awareness, self-management) and intercultural competencies of students and school staff.

\subsection{Instruments}

Interpersonal Reactivity Index (IRI; Davis, 1980) was used as a measure of empathy. It consists of four scales; two of them labelled as emotional empathy (empathic concern, personal distress) and the other two as cognitive empathy (perspective taking, fantasy). Each has 7 items on a 4-point Likert scale (1 - "Never", 4 - "Often"). Cronbach's alpha scores ranged from .65 to .74 (Slovenia) and .61 to .79 (Sweden) and from .66 to .76 (Croatia). Positive class climate (Positives Klassenklima-KLAKL; Stöber, 2002) was used to measure the perceived positive classroom climate. It includes 10 items on a 4-point Likert scale (1 - "Strongly disagree", 4 - "Strongly agree"). Cronbach's alpha scores ranged from .68 (Slovenia) and .76 (Sweden) to .78 (Croatia). The Warwick-Edinburgh Mental Well-being Scale (WEMWBS; Stewart-Brown et al., 2011) was used to assess the perceived well-being of students. It consists of 14 items on a 4-point Likert scale (1 - "Never", 4 - "Often"). Cronbach's alpha scores ranged from .78 (Slovenia) and .79 (Croatia) to .86 (Sweden).

\subsection{Procedure}

From December 2017 to March 2018, students completed a battery of questionnaires tapping SEI competencies and demographic variables either in the paper version (Slovenia and Croatia) or online (Sweden). For the purpose of this study, we only present data for the selected measures. Reliability tests, descriptive statistics, t-test and multiple linear regression for each country were calculated with IBM SPSS Statistics 21.

\section{Results}

In Table 1, we can see the means and standard deviations for the samples from each participating country. Both, Slovenian students as Croatian, report more frequently experiencing emphatic concern than Sweden students, $(t(186)=4,128, p=.000$ and $t(158)=-2,104, p=.037)$. On the other hand, the Croatian students report the most frequently experienced personal distress, significantly higher than in Sweden that has the lowest average at this scale, $t(157)=-2,347, p=.020$. There were no statistically significant differences between countries on other scales.

Table 1. Descriptive statistics of empathy, classroom climate and well-being of students across countries.

\begin{tabular}{|c|c|c|c|c|c|c|}
\hline & \multicolumn{2}{|c|}{ Slovenia } & \multicolumn{2}{|c|}{ Sweden } & \multicolumn{2}{|c|}{ Croatia } \\
\hline & $M$ & $S D$ & $M$ & $S D$ & $M$ & $S D$ \\
\hline \multicolumn{7}{|l|}{ Empathy } \\
\hline Fantasy & 2,523 & 0,650 & 2,483 & 0,617 & 2,570 & 0,627 \\
\hline Empathic concern & 2,964 & 0,497 & 2,693 & 0,502 & 2,853 & 0,637 \\
\hline Perspective taking & 2,613 & 0,499 & 2,594 & 0,637 & 2,613 & 0,532 \\
\hline Personal distress & 2,297 & 0,529 & 2,159 & 0,618 & 2,357 & 0,561 \\
\hline
\end{tabular}

In Table 2, multiple linear regression for each country is presented, with all four subscales of empathy and classroom climate as predictors included. Personal distress, a subscale of empathy is a significant negative predictor in all participating countries and the only significant one in the Croatian sample. If we use personal distress as our only predictor of the selected outcome, it explains 20,6\% (Slovenia), 12,1\% (Sweden) and 9,6\% of the well-being's variance. In the Slovenian sample, emphatic concern is also an important positive predictor. In Sweden, that has 40,7 \% of the well-being variance explained, another empathy subscale (fantasy) is an important positive predictor, and as the only one from our samples, has a significant contribution of the positive classroom climate to the explained variance. 
Table 2. Four components of empathy and positive class climate as predictors of well-being across countries.

\begin{tabular}{|c|c|c|c|c|c|}
\hline & $B(S E)$ & $\beta$ & $t$ & $\mathrm{R}^{2}$ & $\mathrm{R}^{2 *}$ \\
\hline \multicolumn{6}{|c|}{ Slovenia $(F(5,98)=7,293, p=.000)$} \\
\hline Constant & $3,210(, 357)$ & & $8,987 * * *$ & & \\
\hline Fantasy &,$- 008(, 062)$ & $-0,014$ & $-0,137$ & & \\
\hline Empathic concern & ,210 (,091) & 0,265 & $2,309 *$ & & \\
\hline Perspective taking &,$- 023(, 090)$ & $-0,029$ & $-0,253$ & & \\
\hline Personal distress &,$- 381(, 70)$ & $-0,513$ & $-5,441 * * *$ & & \\
\hline Positive class climate &, $069(, 093)$ & 0,069 & 0,750 & 271 & 234 \\
\hline \multicolumn{6}{|c|}{ Sweden $(F(5,69)=9,454 ; p=.000)$} \\
\hline Constant & $2,106(, 436)$ & & $4,834 * * *$ & & \\
\hline Fantasy & $362(, 101)$ & 0,400 & $3,567 * *$ & & \\
\hline Empathic concern &, $046(, 126)$ & $-0,041$ & $-0,361$ & & \\
\hline Perspective taking &,$- 066(, 099)$ & $-0,075$ & $-0,669$ & & \\
\hline Personal distress &,$- 366(, 101)$ & $-0,405$ & $-3,628 * *$ & & \\
\hline Positive class climate & ,459 (,127) & 0,379 & $3,610 * *$ & ,407 & ,364 \\
\hline \multicolumn{6}{|c|}{ Croatia $(\mathrm{F}(5,72)=3,888 ; \mathrm{p}=004)$} \\
\hline Constant & $2,701(, 410)$ & & $6,595 * * *$ & & \\
\hline Fantasy & $0,012(, 078$ & 0,017 & 0,154 & & \\
\hline Empathic concern & $0,088(, 086)$ & 0,127 & 1,026 & & \\
\hline Perspective taking & $0,159(, 092)$ & 0,192 & 1,729 & & \\
\hline Personal distress & $-0,277(, 096)$ & $-0,352$ & $-2,875 * *$ & & \\
\hline Positive class climate & $0,175(, 100)$ & 0,193 & 1,761 &, 213 &, 158 \\
\hline
\end{tabular}

\section{Conclusions}

Our study shows that personal distress (one aspect of empathy), is an important predictor of well-being in all participating countries. This supports the development of an international programme, aiming at reducing its influences. Students that have troubles in regulating their emotions (and distinguishing between their own and feelings of others) and get overwhelmed when someone is in distress (the focus is on themselves and not on the other person) report lower well-being than their peers in all participating countries. One of the examples of intervention could be focused on self- and others awareness (e.g. how to distinguish between our own feelings and feeling of others) and on self-regulation (e.g. regulation of own emotions, thoughts, actions).

\section{References}

Cocoradă, E., \& Orzea, I. E. (2017). Relationships between wellbeing, resilience and school climate. Bulletin of the Transilvania University of Brasov. Series VII, Social Sciences, Law., 10(2), 191-200.

Davis, M. H. (1980). A multidimensional approach to individual differences in empathy. JSAS Catalog of Selected Documents in Psychology, 10, 1-19.

Decety J, Bartal IB-A, Uzefovsky F, \& Knafo-Noam A. (2016). Empathy as a driver of prosocial behaviour: highly conserved neurobehavioural mechanisms across species. Phil. Trans. R. Soc. B 371:20150077.

Eisenberg, N., Fabes, R. A., Murphy, B., Karbon, M., Smith, M., \& Maszk, P. (1996). The relations of children's dispositional empathy-related responding to their emotionality, regulation, and social functioning. Developmental psychology, 32(2), 195.

Jolliffe, D., \& Farrington, D. P. (2006). Examining the relationship between low empathy and bullying. Aggressive behavior, 32(6), 540-550.

Shanafelt, T. D., West, C., Zhao, X., Novotny, P., Kolars, J., Habermann, T., \& Sloan, J. (2005). Relationship between increased personal well-being and enhanced empathy among. Journal of general internal medicine, 20(7), 559-564.

Stewart-Brown, S. L., Platt, S., Tennant, A., Maheswaran, H., Parkinson, J., Weich, S., ... \& Clarke, A. (2011). The Warwick-Edinburgh Mental Well-being Scale (WEMWBS): a valid and reliable tool for measuring mental well-being in diverse populations and projects. Journal of Epidemiology and Community Health, 65(Suppl 2), A38-A39.

Stöber, J. (2002). Skalendokumentation „Persönliche Ziele von SchülerInnen“. Hallesche Berichte zur Pädagogischen Psychologie, 3, 40-41.

Zorza, J.P., Marino, J. \& Mesas, A.A. (2015). The influence of effortful control and empathy on perception of school climate. Eur J Psychol Educ 30:457-472 